\title{
Genetic variations in APPL2 are associated with overweight and obesity in a Chinese population with normal glucose tolerance
}

\author{
Shan Jiang ${ }^{1 \dagger}$, Qichen Fang ${ }^{1 \dagger}$, Weihui Yu', Rong Zhang ${ }^{1}$, Cheng Hư ${ }^{1}$, Kun Dong ${ }^{1}$, Yuqian Bao ${ }^{1}$, Chen Wang ${ }^{1}$, \\ Kunsan Xiang ${ }^{1}$ and Weiping $\mathrm{Jia}^{1,2^{*}}$
}

\begin{abstract}
Background: APPL1 and APPL2 are two adaptor proteins, which can mediate adiponectin signaling via binding to $\mathrm{N}$ terminus of adiponectin receptors in muscle cells. Genes encoding adiponectin and adiponectin receptors contribute to insulin resistance and the risk of obesity, and genetic variants of APPL1 are associated with body fat distribution. However, the association between genetic variations of APPL2 and metabolic traits remains unknown. In the current study, we aimed to test the impacts of APPL2 genetic variants on obesity in a Chinese population with normal glucose tolerance.
\end{abstract}

Methods: We genotyped six single nucleotide polymorphisms (SNPS) in APPL2 in 1,808 non-diabetic subjects. Overweight and obesity were defined by body mass index (BMI). Obesity-related anthropometric parameters were measured, including height, weight, waist circumference, hip circumference. BMI and waist-hip ratio (WHR) were calculated.

Results: We found significant evidence of association with overweight/obesity for rs2272495 and rs 1107756. rs2272495 C allele and rs1107756 T allele both conferred a higher risk of being overweight and obese (OR 1.218, $95 \% \mathrm{Cl} 1.047-1.416, p=0.011$ for rs2272495; OR 1.166, 95\% Cl 1.014-1.341, $p=0.031$ for rs 1 107756). After adjusting multiple comparisons, only the effect of rs 2272495 on overweight/obesity remained to be significant (empirical $p=$ 0.043). Moreover, we investigated the effects of these SNPs on obesity-related quantitative traits in all participants. rs2272495 was associated with BMI $(p=0.015)$, waist circumference $(p=0.006)$, hip circumference $(p=0.025)$ as well as WHR ( $p=0.047$ ) under a recessive model. Similar associations were found for rs1107756 except for WHR.

Conclusion: This study suggests that genetic variations in APPL2 are associated with overweight and obesity in Chinese population with normal glucose tolerance.

\section{Background}

In recent years, the worldwide prevalence of obesity has increased dramatically and has became a major global epidemic impacting on morbidity and mortality. According to data from World Health Organization (WHO), more than 1 billion adults are overweight worldwide and at least 300 million are clinically obese [1].

\footnotetext{
* Correspondence: wpjia@sjtu.edu.cn

+ Contributed equally

'Shanghai Diabetes Institute, Shanghai Key Laboratory of Diabetes Mellitus, Shanghai Clinical Center for Diabetes, Department of Endocrinology and Metabolism, Shanghai Jiao Tong University Affiliated Sixth People's Hospital, Shanghai, China

Full list of author information is available at the end of the article
}

Although the developments of obesity are mainly attributed to environmental and behavioural factors such as a sedentary habit and overly rich nutrition, multiple genetic components do predispose to this disease, which is suggested by genome-wide association studies (GWAS) and genetic epidemiologic researches [2]. Up to now, GWAS have identified approximately 50 loci associated with obesity [3].

Adaptor protein, phosphotyrosine interaction, $\mathrm{PH}$ domain and leucine zipper containing 1 (APPL1) and Adaptor protein, phosphotyrosine interaction, $\mathrm{PH}$ domain and leucine zipper containing 2 (APPL2) are two adaptor proteins, which can mediate adiponectin
C Biomed Central

(c) 2012 Jiang et al; licensee BioMed Central Ltd. This is an Open Access article distributed under the terms of the Creative Commons Attribution License (http://creativecommons.org/licenses/by/2.0), which permits unrestricted use, distribution, and reproduction in any medium, provided the original work is properly cited. 
signaling via binding to $\mathrm{N}$ terminus of adiponectin receptors in muscle cells [4-6]. They are both highly expressed in insulin-target tissues, including skeletal muscle, liver and adipose tissue [4,7]. APPL1 and APPL2 were found to share $54 \%$ identity in protein sequences and be encoded by gene on human chromosomes 3 and 12, respectively [6]. Our previous study has demonstrated that genetic variants of APPL1 are correlated with body fat distribution in Chinese type 2 diabetic patients [8]. However, to date, there is no study available concerning the association between genetic variations of APPL2 and metabolic traits. Therefore, we investigated the association of APPL2 with obesity and obesity-related quantitative traits in a Chinese non-diabetic population.

\section{Methods \\ Participants}

The present study included 1,806 non-diabetic adult individuals (age $\geq 19$ ) of Han Chinese ancestry who participated in the community-based Shanghai Diabetes Studies [9]. The detailed inclusion and exclusion criteria for all subjects have been described previously [9]. Briefly, all the individuals were with normal glucose regulation, over 40 years old and with no family history of diabetes. And the normal glucose tolerance defined as fasting plasma glucose level $<6.1 \mathrm{mmol} / \mathrm{l}$ and $2 \mathrm{~h}$ plasma glucose level of $75 \mathrm{~g}$ OGTT $<7.8 \mathrm{mmol} / \mathrm{l}$. BMI was used to assess generalized obesity according to the Chinese criteria that classified all individuals into three groups: normal weight $\left(B M I<24 \mathrm{~kg} / \mathrm{m}^{2}\right)$, overweight $\left(24 \leq \mathrm{BMI}<28 \mathrm{~kg} / \mathrm{m}^{2}\right)$ and obese $\left(\mathrm{BMI} \geq 28 \mathrm{~kg} / \mathrm{m}^{2}\right)$ [10]. The clinical characteristics of three groups were given in Table 1. All study participants gave written informed consent, and study protocols were approved by the institutional review board of Shanghai Jiao Tong University Affiliated Sixth People's Hospital.

\section{Clinical measurement}

All participants underwent detailed clinical investigations as described previously [9]. In brief, anthropometric parameters, including height, weight, waist and hip circumference were measured in all subjects. BMI was calculated as weight in kilograms divided by the square of height in meters and waist-to-hip ratio (WHR) was calculated as waist circumference $(\mathrm{cm}) / \mathrm{hip}$ circumference $(\mathrm{cm})$.

\section{Single nucleotide polymorphism (SNP) selection and genotyping}

In the present study, we selected six tagging SNPs in APPL2 from the HapMap Phase 3 Chinese population including rs935251, rs10861360, rs1196744, rs1196768, rs3751191 and rs1107756 together with one non-synonymous SNP (rs2272495) in exon15. The figure S1 (see Additional file 1) shows linkage disequilibrium plot of all variants within APPL2 using CHB data of HapMap version 3 Release 27 and highlights the SNPs selected in our study. All the seven SNPs were genotyped by primer extension of multiplex products with detection by matrix-assisted laser desorption/ionisation time-of-flight mass spectroscopy using a MassARRAY platform (MassARRAY Compact Analyzer; Sequenom, San Diego, CA, USA). rs935251 is excluded because of genotyping failure and rs1196744 because of departure from HardyWeinberg equilibrium ( $p=6.76 \mathrm{E}-56)$. The remaining five SNPs could tag $93 \%$ SNPs with a minor allele frequency (MAF) of $>0.1$ from $18.9 \mathrm{~kb}$ upstream to $7.5 \mathrm{~kb}$ downstream of APPL2 based on an $\mathrm{r}^{2}$ of $\geq 0.7$. The call rates for rs2272495, rs10861360, rs1196768, rs3751191 and $\mathrm{rs} 1107756$ were $97.0 \%, 95.6 \%, 96.3 \%, 96.5 \%$ and $96.8 \%$, respectively. The concordance rates based on 100 duplicates were over 99\% for all these SNPs.

\section{In silico prediction of the functionality of APPL2 SNPs}

PolyPhen2 (Polymorphism Phenotyping v2), a revised version of PolyPhen, is a tool which can predict the possible impact of missense mutations on the structure and function of encoded proteins. The prediction is based on performing various sequence and structure analyses. We assessed the functionality of coding variant (rs2272495) using PolyPhen2. The outputs of predictions

Table 1 Clinical characteristics of study population

\begin{tabular}{|c|c|c|c|}
\hline & Normal Weight & Overweight & Obesity \\
\hline Samples (n) & 1046 & 601 & 159 \\
\hline Male/Female (n) & $443 / 603$ & $244 / 357$ & $60 / 99$ \\
\hline Age (years) & $57.04 \pm 12.76$ & $57.49 \pm 11.81$ & $58.50 \pm 11.37$ \\
\hline BMI $\left(\mathrm{kg} / \mathrm{m}^{2}\right)$ & $21.72(20.27,22.81)$ & $25.61(24.79,26.64)$ & $29.29(28.48,31.04)$ \\
\hline Waist circumference $(\mathrm{cm})$ & $73.50(69.00,78.00)$ & $84.00(79.00,89.00)$ & $93.50(88.00,98.00)$ \\
\hline Hip circumference (cm) & $89.00(85.00,92.00)$ & $95.50(93.00,99.00)$ & $102.00(99.00,105.00)$ \\
\hline$\overline{W H R}$ & $0.83(0.79,0.87)$ & $0.88(0.84,0.92)$ & $0.91(0.87,0.92)$ \\
\hline
\end{tabular}

Abbreviation: $B M I$ body mass index; WHR waist to hip ratio.

Data are shown as mean \pm SD or median (interquartile range). 
are cataloged as benign, possibly damaging or probably damaging. PolyPhen2 is available at http://genetics.bwh. harvard.edu/pph2.

\section{Statistical analysis}

$\chi^{2}$ test was performed to estimate Hardy-Weinberg equilibrium for each variant before association analyses. Pairwise linkage disequilibrium was estimated for all DNA samples via calculating $\left|D^{\prime}\right|$ and $r^{2}$ using Haploview (version 4.2) [11]. Haplotype block structure was assessed by confidence interval algorithm [12]. Expectation-Maximization algorithm were used to estimated Haplotype frequencies by Haploview (version 4.2) [13]. The allelic and haplotype frequencies were compared using $\chi^{2}$ tests between overweight and obese subjects and those with normal weight. Odds ratios (ORs) with 95\% confidence intervals (CIs) were presented. Associations of SNPs with obesity-related measurements were assessed under a recessive model. Non parametric approach of rank transformation was performed to assess the contrasts results among three genotypes. Skewly distributed quantitative traits, including BMI, waist circumference, hip circumference and WHR were $\log _{10}$ transformed to approximate univariate normality before analysis. For adjusting multiple comparison, 10,000 permutations were performed to assess empirical $p$ values using PLINK (version1.07) [14]. All statistical analyses were performed using SAS for Windows (version 8.0; SAS Institute, Cary, NC, USA) unless specified otherwise. A two-tailed $p$ value $<0.05$ was considered significant. We estimated study power using QUANTO. Assuming an additive model with the minor allele frequencies of $0.1,0.2,0.3$ and 0.4 in our Chinese population, our sample size has $0.53,0.77,0.87$ and 0.91 power to detect an OR of 1.25 at an $\alpha$ level of 0.05 .

\section{Results}

Linkage disequilibrium analysis revealed that these five SNPs were in modest linkage disequilibrium and formed two haplotype blocks in this region (Figure 1).

We first examined the associations of these SNPs with the risk of overweight/obesity. Significant evidence of associations with overweight/obesity were observed for rs2272495 and rs1107756. rs2272495 C allele and rs1107756 $\mathrm{T}$ allele both conferred a higher risk of being overweight and obese (OR 1.218, 95\% CI 1.047-1.416, $p$ $=0.011$ for rs2272495; OR 1.166, 95\% CI 1.014-1.341, $p$ $=0.031$ for rs1107756). However, after adjusting multiple comparisons, only the effect of rs2272495 on overweight and obese remained to be significant (empirical $p$ $=0.043)$. We also analysed the correlation between these SNPs and overweight/obesity after adjusting for age and sex. All the SNPs showed similar effects with or without adjustment (Table 2). In the haplotype association analyses, we compared the haplotype distributions between overweight/obesity and normal weight. We observed that the haplotype CG in block 1 (rs1107756rs1196768) and the haplotype TC in block 2 (rs2272495-rs10861360) were associated with overweight/obesity ( $p=0.041$ and $p=0.018$, respectively) (Table 3).

We further investigated the effects of these SNPs at APPL 2 on obesity-related measures, including BMI, waist circumference, hip circumference and WHR in all participants. We found that rs2272495 was associated with BMI $(p=0.015)$, waist circumference $(p=0.006)$, hip circumference $(p=0.025)$ as well as WHR $(p=$ 0.047 ) under a recessive model (Table 4). Similar associations were found for rs1107756 except for WHR (see Additional file 2). The non parametric approach also showed the similar effect of rs2272495 on the BMI, waist circumference and hip circumference ( $p=0.026, p$ $=0.015$ and $p=0.033$, respectively) (see Additional file $3)$. And rs1107756 was only associated with waist circumference ( $p=0.033)$ using non parametric approach (see Additional file 4).

\section{Discussion}

In the present study, we tested five SNPs in APPL2 and identified two novel risk-conferring SNPs, rs2272495 and rs1107756, for overweight and obesity in non-diabetic individuals. We also found these SNPs, especially rs2272495, were associated with obesity-related measures in these subjects.

APPL2 is an isoform of APPL1 and can form a dimer with APPL1 $[15,16]$. APPL1 is a critical regulator in both adiponectin and insulin signaling pathway. APPL1, which binds directly to adiponectin receptors (AdipoR1 and AdipoR2), can positively mediate adiponectin signaling and phosphorylate its downstream molecules, leading to increased glucose uptake and fatty acid oxidation in muscle cells. In addition, APPL1 can enhance the synergistic effect of adiponectin on insulin-stimulated Akt phosphorylation and mediate the cross-talk between adiponectin and insulin signaling pathways [5]. Recently, APPL2 has also been suggested to play an important role in adiponectin and insulin signaling as well as the cross-talk between these two pathways. APPL2 can negatively regulate adiponectin signaling by competing with APPL1 in binding to AdipoR1 in muscle cells. Suppression of APPL2 can promote adiponectin-stimulated glucose uptake and fatty acid oxidation [4]. Although, unlike APPL1, APPL2 does not directly interact with the catalytic subunit of PI3-kinase and Akt2 which are key kinases in the PI3-kinase pathway downstream of the insulin receptor $[15,16]$, APPL2 can suppress insulin signaling by inhibiting the interaction between APPL1 and the components of insulin signaling. Thus, suppression 


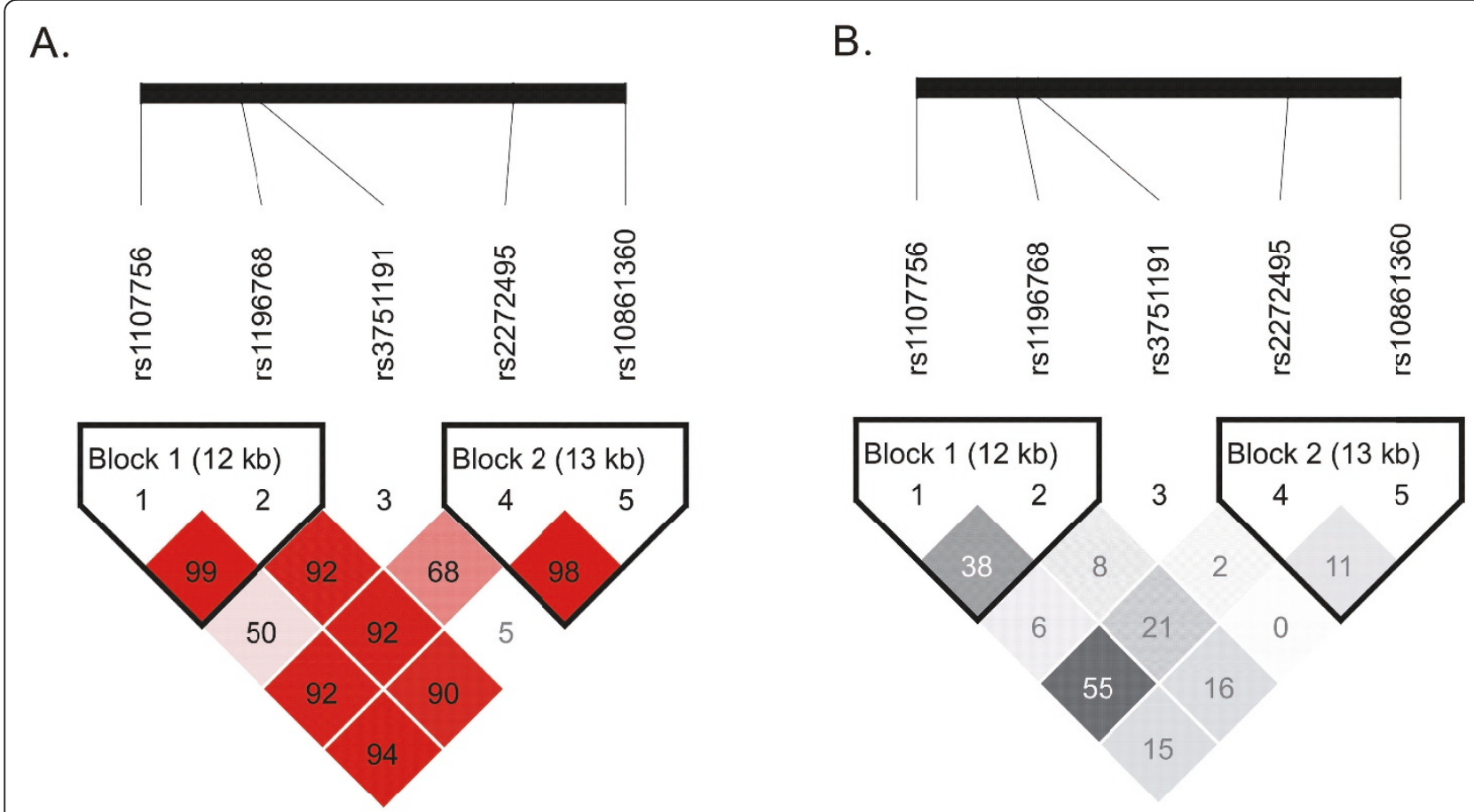

Figure 1 Linkage disequilibrium maps for SNPs genotyped in APPL2 in the Chinese subjects with normal glucose tolerance. A Shades of red demonstrate the strength of the pairwise linkage disequilibrium based on $\left|D^{\prime}\right|$ and numbers indicate the value of $\left|D^{\prime}\right|$ expressed as a percentage. B Shades of grey demonstrate the strength of pairwise linkage disequilibrium based on $r^{2}$, and numbers indicate the value of $r^{2}$ expressed as a percentage.

of APPL2 greatly enhanced the sensitizer effect of adiponectin on insulin [4].

Previously, a link between genes involved in adiponectin signaling and metabolic traits has been suggested by several studies. The adiponectin gene contributes to variances in the plasma adiponectin levels and insulin resistance index and predisposes to obesity and type 2 diabetes [17-19]; the genes encoding adiponectin

Table 2 Associations of APPL2 SNPs with overweight and obesity

\begin{tabular}{|c|c|c|c|c|c|c|c|c|c|c|c|c|}
\hline \multirow[t]{2}{*}{ SNP } & \multirow{2}{*}{$\begin{array}{l}\text { Mayor/ } \\
\text { minor } \\
\text { allele }\end{array}$} & \multirow{2}{*}{$\begin{array}{l}\text { Risk } \\
\text { allele }\end{array}$} & \multicolumn{2}{|c|}{ Overweight + Obesity } & \multicolumn{2}{|c|}{ Normal Weight } & \multirow{2}{*}{$\begin{array}{l}\text { OR } \\
(95 \% \mathrm{Cl})\end{array}$} & \multirow{2}{*}{$\begin{array}{l}p \\
\text { value }\end{array}$} & \multirow{2}{*}{$\begin{array}{l}\text { Empirical } \\
p \text { value }\end{array}$} & \multirow{2}{*}{$\begin{array}{l}\text { OR } \\
(95 \% \\
\text { Cl) \# }\end{array}$} & \multirow{2}{*}{$\begin{array}{l}p \\
\text { value } \\
\#\end{array}$} & \multirow{2}{*}{$\begin{array}{l}\text { Empirical } \\
p \text { value \# }\end{array}$} \\
\hline & & & $\begin{array}{l}\text { Risk allele } \\
\text { frequencies }\end{array}$ & $\begin{array}{l}\text { Genotype } \\
\text { count } 11 / \\
12 / 22^{a}\end{array}$ & $\begin{array}{l}\text { Risk allele } \\
\text { frequencies }\end{array}$ & $\begin{array}{l}\text { Genotype } \\
\text { count } 11 / \\
12 / 22^{a}\end{array}$ & & & & & & \\
\hline rs1107756 & $\mathrm{T} / \mathrm{C}$ & $\mathrm{T}$ & 0.652 & $313 / 326 / 91$ & 0.616 & $391 / 473 / 154$ & $\begin{array}{l}1.166 \\
(1.014- \\
1.341)\end{array}$ & 0.031 & 0.128 & $\begin{array}{l}1.160 \\
(1.009- \\
1.333)\end{array}$ & 0.037 & 0.143 \\
\hline rs1196768 & $G / A$ & A & 0.413 & $253 / 354 / 126$ & 0.387 & $377 / 480 / 149$ & $\begin{array}{l}1.118 \\
(0.974- \\
1.282) \\
\end{array}$ & 0.112 & 0.375 & $\begin{array}{l}1.118 \\
(0.974- \\
1.283) \\
\end{array}$ & 0.113 & 0.376 \\
\hline rs3751191 & $\mathrm{C} / \mathrm{T}$ & $\mathrm{T}$ & 0.135 & $551 / 169 / 15$ & 0.126 & $767 / 228 / 13$ & $\begin{array}{l}1.086 \\
(0.890- \\
1.325) \\
\end{array}$ & 0.416 & 0.868 & $\begin{array}{l}1.088 \\
(0.891- \\
1.329)\end{array}$ & 0.409 & 0.868 \\
\hline rs2272495 & $\mathrm{C} / \mathrm{T}$ & C & 0.746 & $408 / 290 / 43$ & 0.707 & $507 / 416 / 88$ & $\begin{array}{l}1.218 \\
(1.047- \\
1.416)\end{array}$ & 0.011 & 0.043 & $\begin{array}{l}1.216 \\
(1.044- \\
1.415)\end{array}$ & 0.012 & 0.052 \\
\hline rs10861360 & $\mathrm{C} / \mathrm{T}$ & $\mathrm{T}$ & 0.245 & $415 / 266 / 45$ & 0.227 & $604 / 339 / 58$ & $\begin{array}{l}1.104 \\
(0.942- \\
1.294)\end{array}$ & 0.220 & 0.611 & $\begin{array}{l}1.099 \\
(0.939- \\
1.285)\end{array}$ & 0.241 & 0.651 \\
\hline
\end{tabular}

${ }^{a} 11$, major allele homozygotes; 12 , heterozygotes; 22 , minor allele homozygotes.

\# adjust for age and sex.

Significant values are indicated in boldface. 
Table 3 Associations of haplotypes consisting of two SNPs in the APPL2 region with overweight and obesity

\begin{tabular}{llll}
\hline Haplotype & \multicolumn{2}{c}{ Haplotype frequencies } & $p$ value \\
\cline { 2 - 3 } & \multicolumn{2}{c}{ Overweight + Obesity } & Normal Weight \\
\hline Block 1 (rs1107756 - rs1196768) & \\
\hline TA & 0.413 & 0.386 & 0.105 \\
\hline CG & 0.352 & 0.386 & $\mathbf{0 . 0 4 1}$ \\
\hline TG & 0.235 & 0.228 & 0.647 \\
\hline Block 2 (rs2272495-rs10861360) & & \\
\hline CC & 0.499 & 0.480 & 0.289 \\
\hline TC & 0.256 & 0.292 & $\mathbf{0 . 0 1 8}$ \\
\hline CT & 0.244 & 0.226 & 0.219 \\
\hline
\end{tabular}

Significant values are indicated in boldface.

receptors are associated with insulin resistance, liver fat and the risk of type 2 diabetes [20,21]; SNPs in APPL1 are found to be correlated with body fat distribution in Chinese patients with type 2 diabetes [8]. Taken together all these findings, it is conceivable that the gene encoding APPL2, which also participates in adiponectin signaling and indirectly mediates insulin signaling, may also exert an effect on metabolic traits. Consistent with this presumption, our study found an association of APPL2 with overweight/obesity in nondiabetic individuals of Han Chinese ancestry, with rs2272495 C allele and rs1107756 T allele conferring a higher risk of being overweight and obese. It should be noted that obesity is a complex disease that affected by multiple genes and environmental factors. The effect of one genetic variant on obesity and obesity-related traits was limited. Therefore, it is convincible that rs2272495 may affect obesity-related traits according to our results in the Table 4. It is tempting to propose that rs2272495 might be a causal variant for overweight/obesity since it is a strong signal detected in our study and a nonsynonymous variant which substitutes valine to alanine. Although this variant is predicted to be benign by PolyPhen2, whether it has effect on protein function in vivo remains unknown and should be further elucidated by mechanic studies. The rs2272495 and rs1107756 were in same haplotype block and displayed $D^{\prime}=0.92$ and $r^{2}=$
0.55 in our study population. Based on $0.55 \mathrm{r}^{2}$, it is a relatively strong LD. Thus, the associations observed for the rs1107756 may be a marker to reflect the association signal for rs2272495. Nevertheless, the possibility that other SNPs may be etiological cannot be excluded. The mechanisms underlying the association between APPL2 and obesity are still unclear, and need to be further illuminated by functional studies.

Some limitations should be noted in the present study. Firstly, we tested the same association of the SNP with adiposity multiple times without correcting for these additional tests in the Table 4. In fact, after Bonferroni correction, rs2272495 was still associated with waist circumference $(p=0.024)$. Secondly, regarding the Table 4, rs2272495 were associated with obesity-related measures. However, when stratifying according to the 3 subgroups (normal weighted, overweight and obese), no significant association was observed in subgroups (see Additional file 5). As the population included in the present study aged all above 40 years old and age factor may influence the prevalence of obesity, the rate of overweight/obese in our manuscript was higher than reports on obesity in China. Actually, the obesity related phenotypes such as BMI presented in our study were skewed distributed. According to these results (Table 4 and see Additional file 5), we cannot draw solid conclusions that rs2272495 were associated with obesityrelated measures in our subjects. The associations between rs2272495 and obesity related phenotypes may only reflect the association between rs 2272495 and overweight/obesity. Thirdly, although we found associations of rs2272495 and rs1107756 with overweight/obesity and obesity-related measurements, we had not the opportunity to perform a replication another independent sample. Further replications in other cohorts are needed to confirm the influence of genetic variation within this locus on overweight/obesity or metabolic traits in the Chinese population.

\section{Conclusion}

Our data suggest that genetic variations in APPL2 are associated with overweight and obesity in the Chinese

Table 4 Association of rs2272495 in APPL2 with obesity-related measures in all participants

\begin{tabular}{lllll}
\hline rs2272495 & $\mathbf{T T}(\mathbf{n}=\mathbf{1 3 1})$ & $\mathbf{C T}(\mathbf{n}=\mathbf{7 0 6})$ & $\mathbf{C C}(\mathbf{n}=\mathbf{9 1 5})$ & \multicolumn{1}{c}{} \\
\cline { 2 - 5 } & Median (interquartile range) & Median (interquartile range) & Median (interquartile range) & TT + CT VS. CC \\
\hline BMl $(\mathrm{kg} / \mathrm{m} 2)$ & $22.806(21.197,24.844)$ & $23.166(21.193,25.398)$ & $23.459(21.502,25.932)$ & $\mathbf{0 . 0 1 5}$ \\
\hline waist circumference $(\mathrm{cm})$ & $77.000(71.000,83.000)$ & $78.000(71.000,84.000)$ & $79.000(72.000,86.000)$ & $\mathbf{0 . 0 0 6}$ \\
\hline hip circumference $(\mathrm{cm})$ & $91.000(87.000,95.000)$ & $91.500(87.000,96.000)$ & $92.000(88.000,97.000)$ & $\mathbf{0 . 0 2 5}$ \\
\hline WHR & $0.849(0.800,0.898)$ & $0.849(0.809,0.895)$ & $0.857(0.809,0.906)$ & $\mathbf{0 . 0 4 7}$ \\
\hline
\end{tabular}

Abbreviation: $B M I$ body mass index; WHR waist to hip ratio.

$P$ values were assessed under a recessive model.

Obesity related measures under investigation were log transformed before analysis.

Significant values are indicated in boldface. 
subjects with normal glucose tolerance. Further investigations are needed to confirm our findings and demonstrate the mechanisms underlying such association.

\section{Additional material}

Additional file 1: Linkage disequilibrium plot of SNPs within APPL2 using CHB data of HapMap version 3 Release 27. This PDF file contains $\left|D^{\prime}\right|$ measures of linkage disequilibrium for each SNP pair within APPL2 using CHB data of HapMap version 3 Release 27.

Additional file 2: Association of rs1107756 in APPL2 with obesityrelated measures in all participants. This Microsoft Excel file contains detailed information of association between rs1107756 in APPL2 and obesity-related measures, including BMI, waist circumference, hip circumference and WHR, under a recessive model.

Additional file 3: Effect of rs2272495 on obesity-related measures in all participants. This Microsoft Excel file contains detailed information of the differences among three genotypes of rs2272495 for every obesity-related measures using non parametric approach of rank transformation

Additional file 4: Effect of rs1107756 on obesity-related measures in all participants. This Microsoft Excel file contains detailed information of the differences among three genotypes of rs 1107756 for every obesity-related measures using non parametric approach of rank transformation.

Additional file 5: Association of rs2272495 in APPL2 with obesityrelated measures in 3 subgroups (normal weighted, overweight and obese). This Microsoft Excel file contains detailed information of association between rs2272495 in APPL2 and obesity-related measures, in separate groups (normal weighted, overweight and obese), under a recessive model.

\section{Abbreviations}

SNP: Single nucleotide polymorphisms; BMI: Body mass index; WHR: Waisthip ratio; WHO: World Health Organization; GWAS: Genome-wide association studies; APPL1: Adaptor protein, Phosphotyrosine interaction, PH domain and leucine zipper containing 1; APPL2: Adaptor protein, Phosphotyrosine interaction, $\mathrm{PH}$ domain and leucine zipper containing 2; OGTT: Oral glucose tolerance test; MAF: Minor allele frequency; OR: Odds ratios; Cl: Confidence interval; AdipoR1: Adiponectin receptor 1; AdipoR2: Adiponectin receptor 2.

\section{Acknowledgements}

This work was supported by grants from Shanghai Municipality for Basic Research (11JC1409600, 08dj1400601 and 10JC1412400), Project of National Natural Science Foundation of China (30971121, 30800617 and 81170735), National 973 Program (2011CB504001), "Chen Guang" Project (09CG07). We are grateful to all participants in this study. We also thank all laboratory staffs at Shanghai Clinical Center for Diabetes for their dedication in our study.

\section{Author details}

${ }^{1}$ Shanghai Diabetes Institute, Shanghai Key Laboratory of Diabetes Mellitus, Shanghai Clinical Center for Diabetes, Department of Endocrinology and Metabolism, Shanghai Jiao Tong University Affiliated Sixth People's Hospital, Shanghai, China. ${ }^{2}$ Department of Endocrinology \& Metabolism, Shanghai Jiao Tong University Affiliated Sixth People's Hospital, 600 Yishan Road, Shanghai 200233, China.

\section{Authors' contributions}

SJ and QF participated in genotyping, performed statistical analysis and drafted the manuscript. WY participated in genotyping and revised the manuscript. RZ prepared the DNA samples and participated in genotyping. $\mathrm{CH}$ designed the study and revised the manuscript. KD participated in sample collection and prepared the DNA samples. CW participated in the clinical study and revised the manuscript. YB participated in clinical study and contributed to discussion. KX contributed to discussion. WJ supervised the study and revised the manuscript. All authors read and approved the final manuscript.

\section{Competing interests}

The authors declare that they have no competing interests.

Received: 8 November 2011 Accepted: 30 March 2012 Published: 30 March 2012

\section{References}

1. Kelly T, Yang W, Chen CS, Reynolds K, He J: Global burden of obesity in 2005 and projections to 2030. Int J Obes (Lond) 2008, 32(9):1431-1437.

2. Walley AJ, Asher JE, Froguel P: The genetic contribution to non-syndromic human obesity. Nat Rev Genet 2009, 10(7):431-442.

3. McCarthy Ml: Genomics, type 2 diabetes, and obesity. N Engl J Med 2010, 363(24):2339-2350

4. Wang C, Xin X, Xiang R, Ramos FJ, Liu M, Lee HJ, Chen H, Mao X, Kikani CK, Liu F, Dong LQ: Yin-Yang regulation of adiponectin signaling by APPL isoforms in muscle cells. J Biol Chem 2009, 284(46):31608-31615.

5. Mao X, Kikani CK, Riojas RA, Langlais P, Wang L, Ramos FJ, Fang Q, ChristRoberts CY, Hong JY, Kim RY, Liu F, Dong LQ: APPL1 binds to adiponectin receptors and mediates adiponectin signalling and function. Nat Cell Biol 2006, 8(5):516-523.

6. Miaczynska M, Christoforidis S, Giner A, Shevchenko A, UttenweilerJoseph S, Habermann B, Wilm M, Parton RG, Zerial M: APPL proteins link Rab5 to nuclear signal transduction via an endosomal compartment. Cell 2004, 116(3):445-456.

7. Mitsuuchi Y, Johnson SW, Sonoda G, Tanno S, Golemis EA, Testa JR: Identification of a chromosome 3p14.3-21.1 gene, APPL, encoding an adaptor molecule that interacts with the oncoprotein-serine/threonine kinase AKT2. Oncogene 1999, 18(35):4891-4898.

8. Fang QC, Jia WP, Gao F, Zhang R, Hu C, Wang CR, Wang C, Ma XJ, Lu JX, $\mathrm{Xu} \mathrm{J}$, Chen HZ, Xiang KS: Association of variants in APPL1 gene with body fat and its distribution in Chinese patients with type 2 diabetic mellitus. Zhonghua Yi Xue Za Zhi 2008, 88(6):369-373.

9. Hu C, Wang C, Zhang R, Ng MC, Bao Y, So WY, Ma RC, Ma X, Chan JC, Xiang K, Jia W: Association of genetic variants of NOS1AP with type 2 diabetes in a Chinese population. Diabetologia 2010, 53(2):290-298.

10. Bei-Fan Z: Predictive values of body mass index and waist circumference for risk factors of certain related diseases in Chinese adults: study on optimal cut-off points of body mass index and waist circumference in Chinese adults. Asia Pac J Clin Nutr 2002, 11(Suppl 8):S685-693.

11. Barrett JC, Fry B, Maller J, Daly MJ: Haploview: analysis and visualization of LD and haplotype maps. Bioinformatics 2005, 21(2):263-265.

12. Gabriel SB, Schaffner SF, Nguyen H, Moore JM, Roy J, Blumenstiel B, Higgins J, DeFelice M, Lochner A, Faggart M, Liu-Cordero SN, Rotimi C, Adeyemo A, Cooper R, Ward R, Lander ES, Daly MJ, Altshuler D: The structure of haplotype blocks in the human genome. Science 2002, 296(5576):2225-2229.

13. Qin ZS, Niu T, Liu JS: Partition-ligation-expectation-maximization algorithm for haplotype inference with single-nucleotide polymorphisms. Am J Hum Genet 2002, 71(5):1242-1247.

14. Purcell $S$, Neale B, Todd-Brown K, Thomas L, Ferreira MA, Bender D, Maller J, Sklar P, de Bakker PI, Daly MJ, Sham PC: PLINK: a tool set for wholegenome association and population-based linkage analyses. Am J Hum Genet 2007, 81(3):559-575.

15. Nechamen CA, Thomas RM, Dias JA: APPL1, APPL2, Akt2 and FOXO1a interact with FSHR in a potential signaling complex. Mol Cell Endocrinol 2007, 260-262:93-99.

16. Chial HJ, Wu R, Ustach CV, McPhail LC, Mobley WC, Chen YQ: Membrane targeting by APPL1 and APPL2: dynamic scaffolds that oligomerize and bind phosphoinositides. Traffic 2008, 9(2):215-229.

17. Hara K, Boutin P, Mori Y, Tobe K, Dina C, Yasuda K, Yamauchi T, Otabe S, Okada T, Eto K, Kadowaki H, Hagura R, Akanuma Y, Yazaki Y, Nagai R, Taniyama M, Matsubara K, Yoda M, Nakano Y, Tomita M, Kimura S, Ito C, Froguel $P$, Kadowaki T: Genetic variation in the gene encoding adiponectin is associated with an increased risk of type 2 diabetes in the Japanese population. Diabetes 2002, 51(2):536-540.

18. Katsuda Y, Asano A, Murase Y, Chujo D, Yagi K, Kobayashi J, Mabuchi H, Yamagishi M: Association of genetic variation of the adiponectin gene 
with body fat distribution and carotid atherosclerosis in Japanese obese subjects. J Atheroscler Thromb 2007, 14(1):19-26.

19. Menzaghi C, Ercolino T, Di Paola R, Berg AH, Warram JH, Scherer PE,

Trischitta V, Doria A: A haplotype at the adiponectin locus is associated with obesity and other features of the insulin resistance syndrome. Diabetes 2002, 51(7):2306-2312.

20. Vaxillaire M, Dechaume A, Vasseur-Delannoy V, Lahmidi S, Vatin V Lepretre F, Boutin P, Hercberg S, Charpentier G, Dina C, Froguel P: Genetic analysis of ADIPOR1 and ADIPOR2 candidate polymorphisms for type 2 diabetes in the Caucasian population. Diabetes 2006, 55(3):856-861.

21. Stefan N, Machicao F, Staiger H, Machann J, Schick F, Tschritter O, Spieth C, Weigert C, Fritsche A, Stumvoll M, Haring HU: Polymorphisms in the gene encoding adiponectin receptor 1 are associated with insulin resistance and high liver fat. Diabetologia 2005, 48(11):2282-2291.

\section{Pre-publication history}

The pre-publication history for this paper can be accessed here: http://www.biomedcentral.com/1471-2350/13/22/prepub

doi:10.1186/1471-2350-13-22

Cite this article as: Jiang et al.: Genetic variations in APPL2 are associated with overweight and obesity in a Chinese population with normal glucose tolerance. BMC Medical Genetics 2012 13:22.

\section{Submit your next manuscript to BioMed Central} and take full advantage of:

- Convenient online submission

- Thorough peer review

- No space constraints or color figure charges

- Immediate publication on acceptance

- Inclusion in PubMed, CAS, Scopus and Google Scholar

- Research which is freely available for redistribution

Submit your manuscript at www.biomedcentral.com/submit 